\title{
Study of causes and facility based lags in a tertiary care hospital contributing to maternal mortality
}

\author{
Ajit Kumar Nayak, S. Dhivya, Tajma Afzal*
}

Department of Obstetrics and Gynecology, SCB Medical College and Hospital, Cuttack, India

\author{
Received: 31 March 2017 \\ Revised: 17 April 2017 \\ Accepted: 21 April 2017 \\ *Correspondence: \\ Dr. Tajma Afzal, \\ E-mail: afzaltajma@gmail.com
}

Copyright: (c) the author(s), publisher and licensee Medip Academy. This is an open-access article distributed under the terms of the Creative Commons Attribution Non-Commercial License, which permits unrestricted non-commercial use, distribution, and reproduction in any medium, provided the original work is properly cited.

\begin{abstract}
Background: Maternal death is a tragic situation as these deaths occur during or after a natural process like pregnancy. By addressing the three levels of delays i.e., delay in seeking care, delay in reaching care and delay in receiving care; it can be prevented to a fair extent.

Methods: All maternal deaths occurred in SCB Medical College and Hospital, Cuttack between September 2015 to September 2016 included in the study, Antepartum and postpartum events were documented as per the proforma. Opinions of respective faculties regarding diagnosis, treatment, possible preventable factors and any delays and lapses at our set up were obtained.

Results: There were 10060 live births and 121 maternal deaths, giving the hospital based incidence of maternal mortality as 12.02 per 1000 live births. $42.98 \%, 6.61 \%$ and $50.41 \%$ of death were due to Level I, Level II and level III delays respectively. The delays due to unavailability of appropriate facilities in our institution are highlighted. Lack of ICU facility accounted $37.19 \%$ deaths. Unavailability of blood, a delay in surgery, delayed multispecialty referral and required investigation follow it. $91.7 \%$. deaths were preventable.

Conclusions: Hypertension, Obstetric hemorrhage, liver and kidney diseases were mainly responsible for maternal mortality. Facility based maternal death review system help in finding out the constraints in the existing system. It brings a sense of responsibility in all stake holders involved in delivery of $\mathrm{MCH}$ care. It is feasible and cost effective strategy to reach Millennium Development target 5 in extended time frame.
\end{abstract}

Keywords: Antepartum and postpartum, Facility-based lags, Maternal mortality

\section{INTRODUCTION}

Maternal death is a tragic situation as these deaths are not caused by disease but occurred during or after a natural process like pregnancy and most of these deaths are avoidable. ${ }^{1}$ Every time a woman in third world becomes pregnant, her risk of dying is 200 times higher than the risk by a woman in the developed world. $25.7 \%$ of global burden of maternal mortality is contributed by India alone. ${ }^{2}$ Maternal mortality is a sensitive index of quality of health care system and general socio economic development of a community. Maternal mortality is not only a health disadvantage rather than it is a social disadvantage as it puts economic burden on the family, community, Government and nations. High maternal mortality rates indicate poor quality or non-availability of $\mathrm{MCH}$ services. The low status of women in society coupled with low literacy levels prevents the women from taking antenatal care even if the services are available. ${ }^{3}$ At the tertiary center appropriate facilities should be available as they receive many cases referred in severe moribund conditions.

By addressing the three levels of delays i.e. delay in seeking care, delay in reaching care and finally delay in receiving care; maternal deaths can be prevented to fair 
extent. $^{4}$ As revealed above because of the alarming situation of maternal mortality, this prospective study was carried out to identify the causes, preventable factors and facility based lags in the Department of Obstetrics and Gynecology, SCB Medical college and Hospital, Cuttack, Odisha.

\section{METHODS}

This retrospective study entitled "Study of causes and facility based lags in a tertiary care hospital contributing to maternal mortality" was undertaken in the department of Obstetrics and Gynecology, S.C.B Medical College and Hospital, Cuttack, Odisha for a period of one year, from September 2015 to September 2016. All maternal deaths occurring while a woman is pregnant or within 42 days of termination of pregnancy, irrespective of the duration and site of pregnancy, from any cause related or aggravated due to pregnancy or its management were included in the study. But deaths due to incidental and accidental causes were not taken in to account. As it is a tertiary hospital it gets referral cases from rural areas, private nursing homes, municipality hospitals, urban slums and of course its own booked cases. All the registered, emergency and unregistered pregnant women who admitted into the hospital and died were included in the study period.

The antepartum and postpartum events were documented carefully as per the proforma. Opinion of respective faculties regarding diagnosis, treatment, possible preventable factors and delays at our set up was obtained as and when necessary according to the cases concerned. Types of treatment given as well as any lapses were truthfully documented. Various factors related to maternal deaths were critically analyzed especially to find out various causes and facility based lags in our tertiary care hospital, so that preventable steps can be taken contributing to maternal death. Strict confidentiality of the data is maintained. Ethical approval was obtained from institutional ethics committee.

\section{RESULTS}

During the study period of one year there were 100, 60 live births and 121 maternal deaths. Thus, maternal mortality ratio (MMR) per one lakh live birth is calculated to be 1202.78 . So, the hospital based incidence of maternal mortality was estimated as 12.02 per 1000 live births.

Table 1: Age distribution.

\begin{tabular}{lll} 
Age group (Yrs) & No. of cases & $\%$ \\
\hline$<20$ & 2 & 1.65 \\
\hline $20-25$ & 67 & 55.38 \\
\hline $26-30$ & 36 & 29.75 \\
\hline $31-35$ & 14 & 11.57 \\
\hline$\geq 36$ & 2 & 1.65 \\
\hline Total & $\mathbf{1 2 1}$ & $\mathbf{1 0 0}$ \\
\hline
\end{tabular}

Out of 121 deaths, $2(1.65 \%)$ deaths occurred in less than 20 years age group, $67(55.38 \%)$ deaths in age group 2025 years, $36(29.75 \%)$ in 26-30 years, $14(11.57 \%)$ in 31 35 years and $2(1.65 \%)$ were more than 36 years (Table $1)$.

Table 2: Parity distribution.

\begin{tabular}{|lll|}
\hline Parity & No. of cases & $\%$ \\
\hline $\mathrm{P}^{0}$ & 53 & 43.80 \\
\hline $\mathrm{P}^{1}$ & 26 & 21.49 \\
\hline $\mathrm{P}^{2}$ & 27 & 22.31 \\
\hline $\mathrm{P}^{3}$ & 9 & 7.44 \\
\hline$\geq \mathrm{P}^{4}$ & 6 & 4.96 \\
\hline Total & $\mathbf{1 2 1}$ & $\mathbf{1 0 0}$ \\
\hline
\end{tabular}

Out of 121 deaths $43.80 \%$ were nulliparous, $21.49 \%$ were primiparous, $22.31 \%$ were para-2, $7.44 \%$ cases were Para-3 and $4.96 \%$ were grand multi para (Table 2).

Table 3: Socioeconomic status.

\begin{tabular}{|lll|}
\hline Socioeconomic status & No. of cases & $\%$ \\
\hline Low & 112 & 92.56 \\
\hline Middle & 09 & $7.44 \%$ \\
\hline High & 00 & 00 \\
\hline Total & $\mathbf{1 2 1}$ & $\mathbf{1 0 0}$ \\
\hline
\end{tabular}

Women from low socioeconomic status contributed to $92.56 \%$ share of maternal mortality, $7.44 \%$ belonged to middle class and none from high socioeconomic status (Table 3).

Table 4: Literacy.

\begin{tabular}{|lll|}
\hline Education & No. of cases & $\%$ \\
\hline Illiterate & 40 & 33.06 \\
\hline Primary school & 69 & 57.02 \\
\hline High school & 09 & 7.44 \\
\hline University & 03 & 2.48 \\
\hline Total & $\mathbf{1 2 1}$ & $\mathbf{1 0 0}$ \\
\hline
\end{tabular}

Above table depicts $33.06 \%$ were illiterate, $57.02 \%$ were educated up to primary school whereas $7.44 \%$ up to high school and $2.48 \%$ up to university level (Table 4 ).

Table 5: Referral status.

\begin{tabular}{|ll|l|}
\hline Referral status & No. of cases & $\%$ \\
\hline Not referred & 16 & 13.22 \\
\hline Early referred & 37 & 30.58 \\
\hline Late referred & 68 & 56.20 \\
\hline Total & $\mathbf{1 2 1}$ & $\mathbf{1 0 0}$ \\
\hline
\end{tabular}

$30.58 \%$ cases were referred early in time and maximum cases $56.2 \%$ were referred late and $13.22 \%$ women came to the hospital directly (Table 5). 
Maximum deaths occurred in rural population i.e. 99 $(81.81 \%)$ in comparison to $22(18.19 \%)$ from urban area.

Out of 121 cases $27(22.31 \%)$ cases were booked and the rest $94(77.69 \%)$ were unbooked.

Table 6: Degree of anemia.

\begin{tabular}{|lll|}
\hline Degree of anemia & No. of cases & $\%$ \\
\hline Non anemic & 12 & 9.92 \\
\hline Mild anemia & 51 & 42.15 \\
\hline Moderate anemia & 25 & 20.66 \\
\hline Severe anemia & 33 & 27.27 \\
\hline Total & $\mathbf{1 2 1}$ & $\mathbf{1 0 0}$ \\
\hline
\end{tabular}

Out of 121 cases $90.08 \%$ women were anemic. Among them $42.15 \%$ were mildly anemic, $20.66 \%$ were moderately anemic and $27.27 \%$ were severely anemic (Table 6).

Table 7: Mode of delivery.

\begin{tabular}{|lll|}
\hline Mode of delivery & No. of cases & $\%$ \\
\hline Vaginal delivery & 27 & 50 \\
\hline Forceps/ Ventouse & 2 & 3.70 \\
\hline Caesarean section & 25 & 46.30 \\
\hline Total & $\mathbf{5 4}$ & $\mathbf{1 0 0}$ \\
\hline
\end{tabular}

Out of 121 women, 54 delivered in our hospital. 50\% had spontaneous delivery, $3.7 \%$ had assisted vaginal delivery with Forceps or Ventouse and $46.3 \%$ had undergone caesarean section (Table 7).

Table 8: Place of delivery.

\begin{tabular}{|ll|l|}
\hline Place of delivery & No. of cases & $\%$ \\
\hline Home & 12 & 11.21 \\
\hline Institutional & 95 & 88.79 \\
\hline Total & $\mathbf{1 0 7}$ & $\mathbf{1 0 0}$ \\
\hline
\end{tabular}

Out of 107 no deliveries, $88.79 \%$ had institutional deliveries and only $11.21 \%$ delivered at home (Table 8 ).

Table 9: Associated surgeries $(n=22)$.

\begin{tabular}{|ll|}
\hline Associated Surgeries & No of cases \\
\hline Manual Removal of Placenta (MROP) & 1 \\
\hline Laparotomy & 3 \\
\hline Devascularisation Procedure & 5 \\
\hline Subtotal hysterectomy & 6 \\
\hline Total hysterectomy & 6 \\
\hline Bladder injury repair & 1 \\
\hline
\end{tabular}

MROP was done in 1 case, laparotomy in 3 cases, devascularization procedures like uterine artery, ovarian artery and internal iliac artery ligation in 5 cases, subtotal hysterectomy in 6 cases and total hysterectomy in 6 cases. Bladder injury repair was done in one case (Table 9).
Table 10: Admission-death interval.

\begin{tabular}{|lll|}
\hline $\begin{array}{l}\text { Admission-Death } \\
\text { interval (in hours) }\end{array}$ & No of cases & $\%$ \\
\hline$<6$ & 22 & 18.18 \\
\hline $6-12$ & 20 & 16.53 \\
\hline $13-24$ & 16 & 13.22 \\
\hline $25-48$ & 20 & 16.53 \\
\hline$>48$ & 43 & 35.54 \\
\hline Total & $\mathbf{1 2 1}$ & $\mathbf{1 0 0}$ \\
\hline
\end{tabular}

$18.18 \%$ of women succumbed to death within 6 hrs of admission. Admission death interval was $6-12 \mathrm{hrs}$ in $16.53 \%, 13-24 \mathrm{hrs}$ in $13.22 \%, 25-48 \mathrm{hrs}$ in $16.53 \%$ and around one third i.e. $35.54 \%$ died $48 \mathrm{hrs}$ after admission (Table 10).

Table 11: Direct causes $(\mathbf{n = 9 2})$.

\begin{tabular}{|c|c|c|c|c|}
\hline \multicolumn{2}{|c|}{ Direct Causes } & \multicolumn{2}{|c|}{ No of cases } & \multirow{3}{*}{$\begin{array}{l}\% \\
33.05\end{array}$} \\
\hline \multirow{2}{*}{$\begin{array}{l}\text { Hypertensive } \\
\text { disorder }\end{array}$} & Preeclampsia & 12 & \multirow[t]{2}{*}{40} & \\
\hline & Eclampsia & 28 & & \\
\hline \multirow{4}{*}{ Hemorrhage } & Early & 1 & \multirow[t]{4}{*}{19} & \multirow[t]{4}{*}{15.7} \\
\hline & Trimester & & & \\
\hline & A.P.H & 3 & & \\
\hline & P.P.H & 15 & & \\
\hline \multirow[b]{2}{*}{ Sepsis } & $\begin{array}{l}\text { Septic } \\
\text { Abortion }\end{array}$ & 3 & \multirow[t]{2}{*}{15} & \multirow[t]{2}{*}{12.4} \\
\hline & $\begin{array}{l}\text { Puerperal } \\
\text { Sepsis }\end{array}$ & 12 & & \\
\hline \multicolumn{3}{|l|}{ Rupture uterus } & 7 & 5.8 \\
\hline \multicolumn{3}{|c|}{ Ruptured ectopic } & 4 & 3.3 \\
\hline \multicolumn{3}{|c|}{ Pulmonary embolism } & 5 & 4.1 \\
\hline \multicolumn{3}{|c|}{ Suspected amniotic fluid embolism } & 2 & 1.65 \\
\hline
\end{tabular}

Hypertensive disorders were the cause in $33.05 \%$ cases out of which 12 cases were due to preeclampsia and 28 cases were due to Eclampsia. Hemorrhage was the cause in $15.7 \%$ cases, out of which 1 case was in early trimester, 3 were antepartum hemorrhage and 15 were postpartum hemorrhage. Sepsis was responsible in $12.4 \%$ cases, out of 15 cases 3 were due to septic abortion and 12 cases due to puerperal sepsis. The other direct causes were rupture uterus in $5.8 \%$, rupture ectopic in $3.3 \%$, pulmonary embolism in $4.1 \%$ cases and suspected amniotic fluid embolism in $1.65 \%$ cases (Table 11 ).

Out of 121 deaths $4.96 \%$ were due to severe anemia, $3.30 \%$ due to malaria, $4.96 \%$ due to jaundice, $6.61 \%$ died due to renal failure and $2.47 \%$ died due to heart disease. One case $(0.83 \%)$ died due to ARDS (pulmonary TB) and one case $(0.83 \%)$ due to Diabetic ketoacidosis (Table 12).

Direct causes to be responsible in $92(76.03 \%)$ cases and whereas indirect causes were accounted for 29 cases (23.97\%). Level I delay was present in 52(42.98\%), Level II delay in $8(6.61 \%)$ and Level III delay contributed $61(50.41 \%)$ maternal deaths. 
Table 12: Indirect causes $(\mathrm{n}=29)$.

\begin{tabular}{|lll|}
\hline Indirect causes & No of cases & $\%$ \\
\hline Anemia & 6 & 4.96 \\
\hline Malaria & 4 & 3.30 \\
\hline Jaundice & 6 & 4.96 \\
\hline Acute Renal Failure & 8 & 6.61 \\
\hline Heart disease & 3 & 2.47 \\
\hline ARDS & 1 & 0.83 \\
\hline Diabetic keto-acidosis & 1 & 0.83 \\
\hline
\end{tabular}

Out of 121 maternal deaths $52(42.98 \%)$ made a delay from onset of complication to deciding seeking care, 50 $(41.32 \%)$ were referred late from peripheral hospitals. Transportation was a problem in $15(12.4 \%)$ cases. In 4 $(3.3 \%)$ cases of rupture uterus lack in appropriate skill at peripheral level was observed.

Table 13: Facility based lags in tertiary care centre

\begin{tabular}{|llc|}
\hline Facility based lags & No of cases & $\%$ \\
\hline Lack of ICU & 45 & 37.19 \\
\hline Unavailability of blood & 18 & 14.87 \\
\hline $\begin{array}{l}\text { Delay in multispecialty } \\
\text { referral }\end{array}$ & 12 & 9.92 \\
\hline Delay in investigations & 1 & 0.83 \\
\hline Delay in surgery & 2 & 1.65 \\
\hline
\end{tabular}

Lack of vacancy in ICU for ventilator support was found to be the most common factor accounting for $37.19 \%$ maternal deaths. Unavailability of blood was found in $14.87 \%$ cases. In $1.65 \%$ cases there was delay in surgery, Multispecialty referral was delayed in $9.92 \%$ cases and delay in the required investigations seen in $0.83 \%$ cases (Table 13).

In present study $111(91.7 \%)$ of the deaths were preventable whereas non-preventable deaths accounted for 10 no i.e. $8.3 \%$.

\section{DISCUSSION}

The hospital based incidence of maternal mortality ratio (MMR) in our study is 1202.78 per one lakh live birth. Though it is difficult to obtain the actual statistics in India, numerous institutional studies have been conducted which serve as a window to actual facts and figures.

Sapre, Joshi Krh reported institutional based MMR ratio of 1448.65 per 1 lakh live birth which is similar to our study. ${ }^{5}$ Bhattacharya et al and Daba et al reported MMR of 599.3 and 953 per 1 lakh live birth respectively in their hospital based study. 6,7

S. Khare et al, Jain et al and Omo-Aghoja et al reported very high hospital based MMR ratio i.e. 2642.77, 2269.40 and 2282 per 1 lakh live birth respectively. ${ }^{8-10}$ Whereas Wagaarachi 2356 and Fernando, Kauser et al and Wani et al reported low MMR i.e. 98.5, 289.58 and
131 per 1 lakh live birth respectively in their hospital based study. ${ }^{11-13}$

The maternal mortality ratio is quite high in our institution which is well above the national and state figures. This may be explained by the fact that it is a tertiary level reference centre where complicated cases from peripheral areas are referred. Often the women are only transported to hospital when they develop life threatening complications, which are too late and swells the number of hospital deaths. In the present study, the minimum age at death was 19 years and the maximum age was 40 years. The mean age was 24.08 years. This increased incidence of maternal mortality in this age group could be because of the fact that maximum number of patients do deliver in this group. In developing countries usually there is a custom of early marriage and early child bearing. In contrast maternal mortality figures at extremes of age are a risk factor. As too early, too late and too close pregnancies affect adversely a woman's health.

In our study $81.81 \%$ belonged to rural area and from low socio-economic class $(92.56 \%)$. Underlying causes may be poverty, illiteracy, harmful birth practices and cultural beliefs. ANC had the advantage of identifying, preventing and managing the complications at an early stage. One satisfactory outcome was increased institutional deliveries $(88.79 \%)$. It may be due to the impact of various Government schemes. $56.2 \%$ patients being referred late and among $35.54 \%$ of maternal death, admission to death interval was $>48$ hours.

It is interesting to note that the commonest cause of maternal death in this study was not due to haemorrhage but due to hypertensive disorder of pregnancy $(33.05 \%)$ which is comparable to reporting done by Shah et al $34.2 \%{ }^{14}$ Whereas Priya et al and Singh et al reported $27.83 \%$ and $24.01 \%$ of death were due to hypertensive disorder respectively. ${ }^{15,16}$

The incidence of deaths due to hemorrhage is on the declining trend. In our study $15.7 \%$ of obstetric death were due to haemorrhage which is comparable to reporting done by Singh et al i.e. $16.11 \% .{ }^{16}$ Chandrika $\mathrm{S}$ Kodla and Gupta et al in their study reported that $21.37 \%$ and $30 \%$ of maternal death were due to Obstetric haemorrhage respectively. ${ }^{17,18}$

In the present study, $12.4 \%$ of maternal deaths were due to sepsis whereas Rajaraman et al reported $41.9 \%$ of death was due to sepsis which is higher in comparison to our study. ${ }^{19}$ Maternal death due to sepsis is on declining trend due to availability of broad-spectrum antibiotics, adhering to strict aseptic technique, timely obstetric interference and better laboratory facility for sepsis screening.

Rupture uterus contributed $5.8 \%$ of maternal death in the present study. Whereas Rajaraman et al and Purandare et 
al reported $9.3 \%$ and $6.67 \%$ of maternal death were due to rupture uterus respectively. ${ }^{19,20}$ Embolism was responsible for $5.8 \%$ of death in our study whereas Bangal et al reported $8.1 \%$ of death was due to embolism. $^{21}$

In the present study $42.98 \%, 6.61 \%$ and $50.41 \%$ of death were due to level I, level II and level III delays respectively which is comparable to study done by Bangal et al and Okonofua et al where $46.42 \%$ and $40 \%$ of death were due to level I delay respectively. ${ }^{21,22} \mathrm{Cham}$ et al and Urasse et al reported $96.87 \%$ and $77.41 \%$ of maternal death were due to level III delay respectively. ${ }^{23,24}$

The level I and II delays relate directly to the issue of care encompassing factors in the family and community while third delay is connected with factors related to health facility and quality of care. Reducing the third delay, that is improving the quality and scope of care available at existing medical facilities, will have the greatest impact in reducing the needless maternal deaths. Lack of transportation and appropriate skill at periphery, Lack of ICU care, Unavailability of blood due to large requirements, delay in investigations and delayed multicentric referral was made out to be the cause of death. Analysis of 121 maternal deaths in this present study projected that most $(91.7 \%)$ of the deaths were preventable whereas only $8.3 \%$ deaths were nonpreventable. It is a fact that majority of direct obstetric deaths were preventable.

\section{CONCLUSION}

In our study the maternal mortality ratio is quite high which is well above the national and state figures. This may be explained by the fact that it is a tertiary level referral centre where complicated cases from peripheral areas are referred. Often the women are only transported to hospital when they develop life threatening complications, which are too late and swells the number of hospital deaths. Maternal deaths were higher in reproductive age group i.e. between 20-25 years $(55.38 \%)$ and more were nullipara $(43.8 \%)$ compared to primipara and higher order of birth. $91.7 \%$ of maternal death were preventable. $76 \%$ of pregnant women died due to direct causes and $24 \%$ due to indirect causes. $90.08 \%$ of pregnant women who died were anemic and $92.56 \%$ came from low socioeconomic status, $81.81 \%$ belonged to rural area, $22.31 \%$ were booked cases and $56.2 \%$ had late referral to our institution. Among the direct cause hypertensive disorders in pregnancy and hemorrhage, followed by sepsis were the leading cause and among the indirect causes renal failure, jaundice, anemia and malaria were the major causes for maternal death. Among the causes and facility based lags, lack of vacancy in the ICU at the time of need followed by inadequate availability of blood were major contributing factors towards maternal death in our tertiary care hospital during the study period. Hence by strengthening of various infrastructures like adequate ICU facilities, 24 hour availability of blood for transfusion, timely investigations, multidisciplinary approach and timely surgery of the indicated cases by expert hand will definitely reduce maternal death to a great extent.

\section{ACKNOWLEDGEMENTS}

Authors are very much thankful to the staffs, doctors and faculties of Department of Obstetrics and Gynecology S.C.B Medical College, Cuttack, Odisha for their timely support while conducting this study.

Funding: No funding sources Conflict of interest: None declared

Ethical approval: The study was approved by the Institutional Ethics Committee

\section{REFERENCES}

1. Park K. Preventive Medicine in Obstetric, Paediatrics and Geriatrics: Park's Text Book of Preventive and Social Medicine. 18th Ed Jabalpur: M/S Banarasi Das Bhanot; 2007:414.

2. WHO. The World Health Report. Make Every Mother and Child Count, Geneva WHO;2005.

3. Chandhiok N, Dhillion B.S, Kambo I, Saxena NC. Determinants of antenatal care Utilisation in rural areas of India. J Obstet and Gynaecol India. 2006;56(1):47-52.

4. Thaddeus S, Maine D. Far too walk: maternal mortality in context. Social Sci Medicine. 1994;38(8):1091-110.

5. Sapre S. Anemia - a most preventable cause of maternal mortality. J Obstet Gynecol India. 2001;51:23-4.

6. Bhattacharya, Kumar S, Majhi. Maternal Mortality in India: A 20 Years Study from a Large Referred Medical College Hospital, West Bengal. J Obs Gynaecol Res. 2008;34:499-503.

7. El Daba AA, Amr TM, Marouf HM, Mostafa M. Retrospective study of maternal mortality in a tertiary hospital in Egypt. Anesth Essays Res. 2010:4:29-32.

8. Khare S, Singh KN, Kalkur S. Maternal mortality in Jabalpur Medical College (A 15-year study). J Obstet Gynaecol India. 2002;52:51-52.

9. Jain M, Maharhaje S. Maternal mortality - a retrospective analysis of ten years in a tertiary hospital. Indian J Prev Soc Med. 2003;34(3\&4):10311.

10. Omo-Aghoja LO, Asiien OA, Akuse JT, Bergstrom S, Okonofua FE. Maternal mortality and emergency obstetric care in Benin City, South-South Nigeria. J Clini Medic Res. 2010;2(4):55-60.

11. Wagaarachi PT, Fernando L. Trends in maternal mortality and assessment of substandard care in a tertiary care hospital. Eur J Obstet Gynecol Reprod Biol. 2002;101(1):36-40. 
12. Kauser S, Khalid S, Yousaf F, Akbar M. Maternal mortality in a tertiary care hospital, lahore- a four year review. E:/Biomedica. 2006;22:8.

13. Wani RJ, Chikhal P, Sonwalkar D. Maternal Mortality: Preventable Tragedy? Bombay Hospital J. 2009;51(4):426-39.

14. Shah N, Khan NH. Third delay of maternal mortality in a tetiary hospital. Rawad Med J 2007;32:163-7.

15. Priya N, Verma A, Verma S. Maternal mortality: ten years retrospective study. JK Sci. 2010;12(3):134-6.

16. Singh R, Sinha N, Bhattacharya K, Ram R. Pattern of maternal mortality in a tertiary care hospital of Patna, Bihar. Indian $\mathrm{J}$ Community Med. 2009;34(1)73-74.

17. Kodla CS. A Study of prevalence, causes, risk factors and outcome of severe obstetric haemorrhage. J Scienti Innov Res. 2015;4(2):83-7.

18. Gupta N, Vaid S, Acharya V. A Prospective Clinical Study of 70 cases of obstetric haemorrhage. J Obste Gyn India. 1994;41(1-3):52-5.

19. Rajaraman P, Agarwal A, and Swain S. Determinents of maternal mortality: a hospital based study from South India. Indian J Maternal Child Health. 1995;6:7-10.
20. Purandare N, Chandock AS, Upadhya S, Sanjanwala SM, Sraogi RM. Maternal mortality at a refferal centre: a five year study. J Obstet Gynaecol India. 2007;57(3):248-50.

21. Bangal VB, Dentia F, Kunal A. Facility based death review at tertiary care teaching hospital. An observational study. Sch J App Med Sci. 2016;4(2c):494-9.

22. Okonofua FE, Abejide OR, Makanjuola RO. Maternal Mortality in Ile-Ife, Nigeria: A Study of Risk Factors. Stud Family Plann. 1992;23(5):319-24.

23. Cham M, Sundby J, Vangen S. Maternal mortality in rural gambia, a qualitative study on access to emergency obstetric care. Reprod Health. 2005;2:3.

24. Urasse E, Massawe S, Gunilla L, Lennarth N. Operational factors affecting maternal mortality in Tanzania. Health Policy and Plan. 1997;12(1):50-7.

Cite this article as: Nayak AK, Dhivya S, Afzal T. Study of causes and facility based lags in a tertiary care hospital contributing to maternal mortality. Int J Reprod Contracept Obstet Gynecol 2017;6:2044-9. 